\title{
UMA EXPERIÊNCIA COM A AUTOAVALIAÇÃO NO CURSO DE LETRAS
}

\author{
Déborah SCHEIDT
}

\section{Resumo}

Neste trabalho a autora relata uma experiência com a autoavaliação na disciplina de Metodologia do Ensino de Língua Inglesa no Curso de Letras. São levantadas questões referentes à autoavaliação do ponto de vista dos Parâmetros Curriculares Nacionais e das Orientações Curriculares para o Ensino Médio ("avaliação formativa” e "avaliação formativa interativa”, bem como dos preceitos da aprendizagem "tradicional", “independente” e "autônoma”. A seguir, apresentam-se exemplos de uma atividade avaliativa e de um roteiro de autoavaliação que foram realizados com os alunos. A análise dos resultados sugere que, se um estilo de autoavaliação totalmente autônomo talvez ainda não seja possível, a introdução gradual de uma autoavaliação orientada e voltada à realidade do grupo pode trazer resultados bastante positivos.

Palavras-chave: autoavaliação; metodologia do ensino de língua inglesa.

\section{Abstract}

In this work the author reports her experience with self-evaluation in an English teaching methodology course at college level. The author raises some questions related to self-evaluation, from the point of view of the Brazilian Guidelines for Primary and Secondary Education ("formative" and "interactive-formative evaluation"), as well as to the "traditional", "independent" and "autonomous" modes of evaluation. Next, she presents examples of an evaluation assignment and of a self-evaluation guide which were applied to her class. The analysis of the results suggests that, if a totally autonomous self-evaluation style might still be impractical, the gradual introduction of a guided self-evaluation mode, well-tuned to a specific teaching/learning reality can bring very encouraging results.

Key words: self-evaluation; English teaching methodology.

Lecionar qualquer disciplina relacionada à metodologia de ensino em cursos de licenciatura implica em um significativo acréscimo ao já pesado fardo de responsabilidade inerente à profissão de professor. Afinal, o professor de metodologia acaba impondo a si mesmo a missão não só de apresentar e discutir conteúdos, mas de converter suas aulas em modelos vivos das condutas que pleiteia. 
Senti na pele o peso dessa responsabilidade extra quando, no ano de 2006, trabalhei pela primeira vez com a disciplina de Metodologia do Ensino de Língua Inglesa com uma turma de 46 alunos do quinto período do Curso de Letras de uma universidade privada de Curitiba. Como o conteúdo programático previa o estudo e análise dos Parâmetros Curriculares Nacionais para Língua Inglesa no Ensino Fundamental e as Orientações Curriculares para o Ensino Médio, optei pela divisão dos textos dos documentos em 10 partes, a serem apresentadas por grupos de 3-5 alunos cada.

O tema avaliação logo se apresentou como uma das discussões centrais. Afinal os PCNs do ensino fundamental discorrem longamente sobre como a "avaliação não deve ser confundida com testes”, os quais “são meios de se avaliar um aspecto apenas do processo de aprendizagem”, enquanto que a avaliação deveria ser “formativa”, isto é, um "processo contínuo de acompanhamento da aprendizagem como bússola diretiva que determina os ajustes necessários a serem feitos no ensino.”(1998, p. 79). Indo mais além, a "avaliação formativa interativa” consiste em "procedimentos constantes e personalizados envolvendo professor e alunos, a partir de critérios não apenas normativos, mas principalmente pessoais, que irão envolver, da parte do professor, uma reflexão sobre si mesmo (sua auto-avaliação) e sobre os alunos, e, da parte dos alunos, uma auto-avaliação e uma avaliação do professor.” (ibid, p. 80)

Além dos PCNs, nossas leituras também incluíram o prefácio de Tasks for Independent Language Learning (Gardner and Miller, 1996). Nessa introdução os editores classificam os estilos de aprendizagem em três categorias: tradicional, independente e autônoma.

A aprendizagem tradicional, de acordo com o prefácio, é aquela que só acontece na sala de aula, dependendo exclusivamente do que o professor diz e que está amarrada a materiais e conteúdos determinados pelo professor. A avaliação nesse estilo de aprendizagem se dá por testes e provas totalmente controlados pelo professor, que também é o único avaliador do progresso dos alunos. No polo oposto encontra-se a aprendizagem autônoma - um modelo de escola ideal - na qual o próprio aluno planeja e implementa seu plano de estudo, de acordo com objetivos por ele próprio traçados. Esse aluno faz uso de qualquer oportunidade de aprendizagem, tanto dentro como fora da escola e toma suas próprias decisões, inclusive se vai ou não acreditar em 
determinada teoria ou aceitar os conselhos do instrutor/professor. (ibid) Nesse caso, o aluno, que já assumiu o controle sobre sua aprendizagem, também planeja e implementa sua própria avaliação.

Como esse modelo parece ainda bastante distante, os editores consideram mais viável investirmos, num primeiro momento, na aprendizagem independente - um estágio intermediário entre as aprendizagens tradicional e autônoma. Na aprendizagem independente, tarefas - desenvolvidas pelo professor, com a participação dos alunos no processo de decisão - encorajam os aprendizes a começar a assumir a responsabilidade por sua própria aprendizagem. Nesse estilo de educação o professor ensina não só conteúdos, mas também estratégias de aprendizagem.

A tabela abaixo pode facilitar a comparação desses estilos avaliativos:

\begin{tabular}{|l|l|l|l|l|}
\hline \multicolumn{3}{|c|}{ AVALIAÇÃO NOS DIFERENTES ESTILOS DE APRENDIZAGEM } \\
\hline \multicolumn{2}{|c|}{ Tradicional } & \multicolumn{2}{|c|}{ Independente } & \multicolumn{2}{c|}{ Autônoma } \\
\hline Testes e provas são propostos e & O professor desenvolve tarefas e & O aluno planeja e implementa \\
controlados unicamente pelo & estratégias que possam auxiliar o & sua própria avaliação. & O \\
professor, que é o único & aluno a autoavaliar-se. O aluno & professor pode aconselhar o \\
avaliador. & & tem voz ativa no processo. & $\begin{array}{l}\text { aluno, se chamado a tal, ou ser } \\
\text { dispensado do processo. }\end{array}$ \\
\hline
\end{tabular}

Quadro 1 - avaliação nos diferentes tipos de aprendizagem

Enquanto as discussões aconteciam, o fim do bimestre se aproximava, a instituição esperava um resultado numérico sobre o aproveitamento dos alunos, e, obviamente, eu não poderia ignorar tudo o que tínhamos discutido e recorrer à tradicional e famigerada prova bimestral como única forma de avaliação. Decidi então propor a meus alunos algum tipo de autoavaliação que lhes permitisse ter voz ativa no processo avaliativo. Eu estava, porém, consciente de que um salto abrupto da avaliação tradicional para a autônoma podia ser arriscado e prejudicial. Fiquei receosa de que, numa autoavaliação muito aberta e com pouca margem para reflexão (ex: "Que nota você se daria?”), a maioria deles resolvesse se considerar nota 100 e, mesmo sem concordar, eu tivesse que aceitar de forma resignada. ${ }^{1}$

Propus então ao grupo algumas possibilidades. A primeira foi realizar também uma prova escrita, mais ou menos tradicional (anexo 1), mas baseada em situações

\footnotetext{
${ }^{1}$ Interessantemente, como uma colega observou, a possibilidade de os alunos atribuírem-se notas mais baixas do que as que eu lhes conferiria, não me ocorreu nesse momento.
} 
práticas (estudos de caso), que equivaleria a 50\% do peso total. A auto-avaliação seria mais voltada às apresentações feitas grupos e responderia pelos outros 50\%. A segunda proposta foi a de "orientar” a auto-avaliação, numa tentativa de que o aluno pudesse refletir sobre diferentes pontos de seu desempenho e não chegar simplesmente a uma conclusão repentina do tipo “Eu mereço tirar 90.” Criei então um roteiro com 10 tópicos, cada um subdividido em 5 ou 6 subtópicos, para encorajar a reflexão durante o processo autoavaliativo (anexo 2). Apesar de tentar fixar valores para cada tipo de comportamento, tomei o cuidado de incluir o subtópico “outros” em todas as categorias, para que os alunos pudessem criar suas próprias situações e prescrever-se valores diversos dos por mim sugeridos. Uma terceira precaução foi acordar com a turma que eu teria o direito de discordar da autoavaliação e discuti-la com algum aluno específico, caso minhas observações fossem muito destoantes das do aluno. Os alunos receberam as propostas de forma positiva. Ninguém, porém, interveio ou sugeriu caminhos alternativos quando chamados a participar, o que tristemente, pode apontar para o fato que nossa educação, em termos de pensamento crítico independente, ainda está muito longe daquela proposta nas teorias e documentos oficiais. ${ }^{2}$

Fiquei ansiosa para conhecer os resultados. Contrariando minhas expectativas, nenhum aluno conferiu nota $100 \%$ a si mesmo. Alguns se deram $90 \%$, mas a maioria enquadrou-se na casa dos $80 \%$. Indo ao encontro do que eu esperava, ninguém se considerou "abaixo da média” (70\%), mesmo aqueles alunos que eu observei que nem sequer tinham exemplares dos textos. Além disso, ninguém fez uso da categoria “outros” talvez porque eu tenha sido um tanto extensiva nos tópicos do questionário, ou quem sabe por falta de familiaridade dos alunos com esse tipo de avaliação, o que gera um pouco de receio em se expor. Evitei intervir nos resultados, com exceção do caso de duas alunas, que não compareceram para apresentar o trabalho do grupo, mas ignoraram esse fato (bastante objetivo) ao preencher o questionário. Elas foram orientadas a refazer o questionário de forma mais sincera e aí obtiveram nota abaixo da média nessa parte da avaliação.

Uma surpresa ficou por conta de um aluno geralmente visto pelo grupo e pelos professores como bastante responsável e participativo e que sempre tirava notas altas, que admitiu que gostaria de ter lido e feito mais durante o bimestre e prescreveu-se

\footnotetext{
${ }^{2}$ Numa próxima oportunidade, a elaboração do próprio roteiro de avaliação será desenvolvida pelo grupo, na sala de aula.
} 
70\%. Esse fato me levou a refletir sobre os fatores subjetivos contraproducentes envolvidos numa autoavaliação, tais como diferentes expectativas e níveis individuais de exigência - tanto da parte do professor como dos alunos - autoestima muito alta ou muito baixa, perfeccionismo, pretextos diversos, e até mesmo desonestidade. Confesso que não sei bem como lidar com isso.

No futuro e num outro contexto educacional, talvez todos nós tenhamos maturidade para reconhecer e trabalhar com esses percalços. Mas, mesmo na situação atual, a experiência aqui relatada mostrou que, apesar de ainda imperfeita, é possível se pensar na introdução gradual de um processo autoavaliativo nos Cursos de Letras. Para isso é necessária uma interação maior com os alunos, um planejamento cuidadoso e atenção para as necessidades e a realidade de cada grupo.

\section{Referências Bibliográficas}

BRASIL. Secretaria de Educação Fundamental.Parâmetros curriculares nacionais : terceiro e quarto ciclos do ensino fundamental: língua estrangeira / Secretaria de Educação Fundamental. E Brasília :MEC/SEF, 1998. 120 p. Disponível em http://portal.mec.gov.br/seb/arquivos/pdf/pcn_estrangeira.pdf

GARDNER, D. \& MILLER, L. (ed.) Tasks for Independent Language Learning. Alexandria, U.S.A.:TESOL, 1996. 
Anexo 1 - Prova do 1 o semestre de 2006

\section{ESTUDOS DE CASO}

Examine as situações descritas abaixo e teça comentários, relacionando-os aos Parâmetros Curriculares Nacionais para Língua Estrangeira do Ensino Fundamental.

Obs: Após cada situação você encontrará sugestões de onde encontrar, nos PCNs, argumentos para elaborar sua análise, porém você não precisa ficar limitado(a) a essas sugestões.

\section{Os objetivos do ensino de L2 no ensino regular}

O Professor Adonísio diz aos alunos no primeiro dia de aula: "Vocês não vão aprender inglês aqui. Para realmente aprender inglês, vocês precisam frequentar um instituto de línguas." (Parte 1)

A Professora Bromélida diz: "O inglês é importante para que vocês um dia possam sair deste país e ir para os Estados Unidos, onde terão alguma chance de ser alguém na vida." (Parte 3: 0 papel da L2 para construção da cidadania)

O Professor Cornucópio diz: "O inglês vai ajudar vocês a se comunicarem com o mundo e a aprenderem mais sobre si mesmos e sobre o que significa ser brasileiro." (Parte 3: o papel da L2 para construção da cidadania; Parte2: a natureza sociointeracional da linguagem)

\section{Didática e metodologia}

A Professora Doratildes passa algumas frases no quadro para serem traduzidas: "The elephant is grey." "It's cold today" "Give the dog its food", etc. Os alunos usam seus dicionários. Logo após, as frases são corrigidas oralmente. A professora desaprova visivelmente os erros de pronúncia cometidos pelos alunos e os corrige imediatamente. Ela acredita que os erros são nocivos à aprendizagem. 0 próximo exercício é passado no quadro:1. These are....parents (I) 2. I have ..... watch (he) 3 . Is this .... car? (you), etc. Os alunos fazem o exercício e no final 0 professor recolhe os cadernos, pois a atividade vale nota. (Parte 6: Interação e construção da aprendizagem, Parte 5: Concepções teóricas do processo de ensino e aprendizagem)

Já a Professora Escolástica traz o seguinte texto: "We've had an HIV test, but should we use a condom anyway?"Os alunos trabalham em pequenos grupos para encontrar a resposta a 3 perguntas. Eles são desencorajados a tentar traduzir o texto palavra por palavra, mas sim a utilizar instrumentos de leitura que também utilizam ao ler na língua materna, tais como inferência e concentração em palavras-chave. (Parte 4: Relação da L2 com os temas transversais, parte 5: L2 e os alunos dos $3^{\circ}$ e $4^{\circ}$ ciclos e parte 7 Conhecimento de mundo e tipos de texto)

A Professora Franilda convida os alunos a fazerem parte de um programa de troca de e-mails com alunos de uma escola da Irlanda do Sul. Os estudantes irlandeses querem saber mais sobre a realidade brasileira. A Profa. constrói com os alunos um modelo de texto que pode servir de ponto de partida para a interação, partindo de um modelo de texto já existente e de sugestões 
dos alunos.(Parte 2: a natureza sociointeracional da linguagem; Parte 6: objetivos gerais de L1 para o Ensino Fundamental)

A Professora Girândola insiste para que seus alunos da $5^{a}$ série "aprendam a pensar em inglês". De acordo com ela, a interferência da L1 prejudica a aprendizagem da L2. Durante a aula dessa professora, os alunos não trabalham em duplas ou grupos e também quase não fazem perguntas: a configuração da sala é como a de um ônibus - os alunos sentam-se em filas paralelas. (Partes 2 e 3: a relação entre a L1 e a L2; parte 6: construção da aprendizagem e configuração espacial da sala de aula)

\section{Avaliação}

O Professor Hipocampo realiza uma só prova ao final do bimestre, uma "prova de gramática". Todo o desempenho dos alunos é medido nessa ocasião. Os alunos geralmente ficam bastante nervosos e costumam tirar notas baixas. (Parte 8:avaliação) 


\section{Anexo 2 - Roteiro de auto-avaliação \\ METODOLOGIA DE ENSINO DE LÍNGUA INGLESA 2 PROFA DÉBORAH SCHEIDT}

\section{AUTOAVALIAÇÃO}

Depois de tantas discussões sobre desenvolvimento continuado e avaliação formativa, gostaria de propor um modelo de avaliação em que você tivesse um papel mais responsável e ativo. Pensei então nos 10 tópicos auto-avaliativos abaixo. Você deve circular o número de pontos ao lado de cada item que melhor descrever sua atuação durante o bimestre (ou criar seu próprio critério no item "outros") e somar tudo ao final. Você já sabe o quanto é importante que você assuma uma atitude reflexiva e sincera ao responder o questionário. Boa autoavaliação! Um abraço,

Prova: 50 \% da nota + Auto-avaliação: 50 \% da nota

Déborah Nome:

\section{Quanto aos textos dos PCNs e Orientações Curriculares:}

Acessei (copiei, emprestei, etc.) os textos completos (Fundamental e Médio). (0,5)

Acessei os PCNs do Ensino Fundamental completos. $(0,4)$

Acessei as Orientações Curriculares do Ensino Médio completos. ( 0,3)

Acessei somente a parte da minha equipe. $(0,2)$

Não acessei os documentos. $(0,0)$

Outros:

Anteriormente às apresentações:

Li os textos de todas as equipes antecipadamente. $(0,5)$

Li parte dos textos das outras equipes. $(0,4)$

Li somente a parte da minha equipe. $(0,3)$

Li somente a minha parte. $(0,2)$

Não li. $(0,0)$

Outros:

Quanto aos encontros com o grupo para preparar o seminário:

Encontrei-me com meu grupo mais de duas vezes. $(0,5)$

Encontrei-me com meu grupo duas vezes. $(0,4)$

Encontrei-me com meu grupo 1 vez. $(0,3)$

Não me encontrei com o grupo, fiz minha parte sozinho em casa. $(0,2)$

Improvisei minha parte na hora da apresentação. $(0,1)$

Não apresentei. $(0,0)$

Outros:

Quanto ao comparecimento (físico e intelectual) às aulas:

Vim a todas as aulas. $(0,5)$

Vim à maioria das aulas. $(0,4)$

Vim à metade das aulas. $(0,3)$

Vim a poucas aulas. $(0,2)$

Não compareci às aulas. $(0,0)$

Outros: 


\section{Quanto à pontualidade:}

Fui pontual em todos os encontros. $(0,5)$

Fui pontual na maioria dos encontros. $(0,4)$

Fui pontual na metade dos encontros. $(0,3)$

Fui pontual em alguns encontros. $(0,2)$

Nunca fui pontual. $(0,1)$

Não compareci aos encontros. $(0,0)$

Outros:

Quanto à minha atitude durante as apresentações:

Ouvi atentamente a todas as outras apresentações. $(0,5)$

Ouvi atentamente à maioria das apresentações. $(0,4)$

Conversei um pouco com meus colegas durante algumas apresentações, dispersando um pouco a atenção. $(0,3)$

Conversei bastante com meus colegas durante as apresentações, mas ainda assim prestei atenção a algumas apresentações. $(0,2)$

Estava muito cansada(0) e portanto não consegui me concentrar muito. $(0,1)$

Não me lembro de praticamente nada do que os colegas discutiram. $(0,0)$

Outros:

Quanto à participação e emissão de comentários:

Participei de várias apresentações com comentários. $(0,5)$

Participei de algumas apresentações com comentários. $(0,4)$

Participei com um ou dois comentários. $(0,3)$

Gostaria de participar, mas fiquei receosa(0) de me

expor. $(0,2)$

Não consegui pensar em nada para falar. $(0,0)$

Outros:

Quanto à preparação anterior à avaliação escrita:

Li atentamente os PCNs para o Ensino Fundamental. $(0,5)$

Li a maior parte dos PCNs para o E.F. $(0,4)$

Li a metade dos PCNs para o E.F. $(0,3)$

Li uma pequena parte dos PCNs para o E.F. $(0,2)$

Não li novamente os PCNs para o E.F. $(0,0)$

Outros:

Quanto à participação durante a avaliação escrita em duplas:

Participei com no mínimo $50 \%$ das idéias. $(0,5)$

Participei com de 30 a $49 \%$ das idéias. $(0,4)$

Participei com algumas idéias. $(0,3)$

Participei com uma ou duas idéias. $(0,2)$

Não participei. $(0,0)$

Outros:

Quanto ao aproveitamento geral:

Essa disciplina vai interferir muito na minha prática profissional. $(0,5)$

Aprendi muitas coisas úteis durante 0 bimestre. $(0,4)$

Aprendi algumas coisas relevantes. $(0,3)$

Aprendi muito pouco. $(0,2)$

Não consegui apreender o sentido da disciplina. $(0,0)$

Outros:

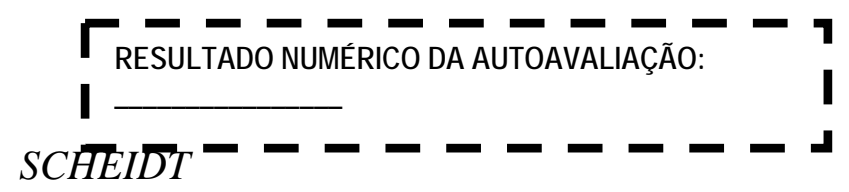

